\title{
Reward magnitude and instrumental responses: Consistent and partial reward ${ }^{1}$
}

\author{
GARVIN McCAIN, University of Texas at \\ Arlington, Arlington, Tex. 76010
}

Two studies using partial or consistent large $(500 \mathrm{mg})$ and small $(45 \mathrm{mg})$ reward are presented. In both studies, after extended reward acquisition, differences are negligible or nonexistent. Results from the partial reward groups indicate extinction differences also disappear after extended training. These results do not seem to be in line with usual assumptions regarding the effects of reward magnitude.

Over the past 2 years a series of studies involving the effects of reward magnitude have been run in this laboratory. This is a preliminary report giving only two of these studies. Several others have been summarized elsewhere (McCain, 1969). The problem of the effects of reward magnitude is critical to a number of interpretations of learning, and the empirical relations are important to almost any learning analysis. The two studies presented followed several studies in which the usual assumption that larger rewards produce more vigorous responses during acquisition was questioned.

\section{EXPERIMENT 1}

This study, as well as a number of other studies in the series, was run as a reward-shift study. The reward-shift data will be presented in a different context. The focus of this study is on comparison of acquisition effects of large $(500 \mathrm{mg})$ and small (45 mg) consistent reward.

Subjects and Apparatus

The Ss were 24 rats of the Wistar strain from the colony of the University of Texas at Arlington. All Ss were approximately 90 days old at the beginning of training. Approximately equal numbers of each sex were used. The straight alley was approximately $6 \mathrm{ft}$ long. Four successive time measures were taken in the alley; the first was for a 12-in. section beginning about 12 in. from the startbox door, the second was about 18 in., and the goal measure was approximately $10 \mathrm{in}$., terminating $8 \mathrm{in}$. from the goal cup. The fourth measure included the time from the startbox door to 8 in. from the goal cup.

Procedure

Ss were placed on 23-h deprivation on Day 1. On Days 2-6, Ss were handled in

Fig. 1. Running times for groups on 45-mg and 500-mg consistent reward schedule. groups for $1 \mathrm{~h}$ daily. Food was available on the handling table during this hour. On Day 7 , Ss were assigned to groups on a random basis. Each $S$ explored the runway for $5 \mathrm{~min}$ daily on Days 7-9. After exploration, Ss were returned to their home cages and, about $15 \mathrm{~min}$ later, each S received his appropriate training reward in a goal cup. A few minutes later, an appropriate amount of lab blocks was given to total $15 \mathrm{~g}$ when added to the reward. Ss were maintained on $15 \mathrm{~g}$ total daily food for the remainder of the study. On Days 10 and 11 , each $S$ received two trials per day and four trials on Days 12 and 13. Six trials per day were given throughout the remainder of training. Ss were brought into the running room in squads of six in a carrying cage with individual compartments. Each $S$ was given a single trial in rotation. This procedure gives an intertrial interval of approximately $6 \mathrm{~min}$. Equal numbers of Ss from each group were arranged in a random order in each squad. The two groups were designated on the basis of their reward schedule, 1-500 (a single $500-\mathrm{mg}$ Noyes pellet on each trial) and 1-45 (one 45-mg Noyes pellet per trial). All Ss received 54 acquisition trials.

\section{Results}

Figure 1 shows the acquisition data for the full runway measure. As may be noted, Group 1-500 has substantially shorter running times over the early stages of training. Analysis of the first 4 days of acquisition gives a significant difference

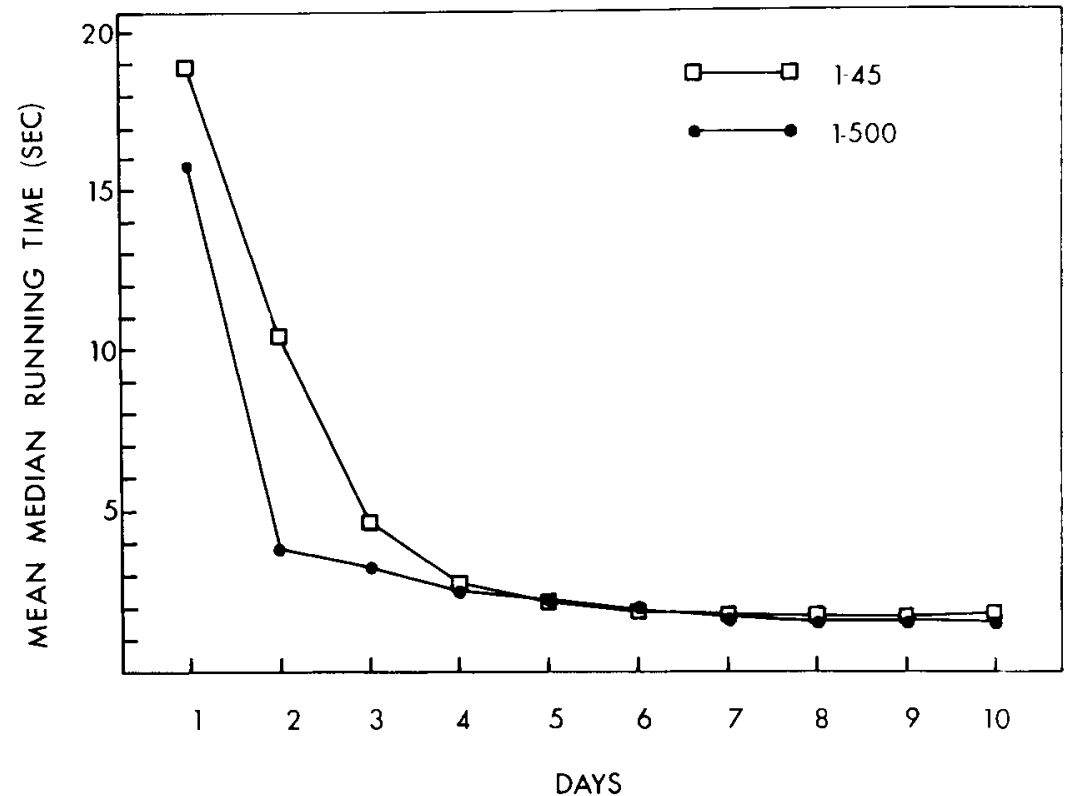

$(F=6.94, \mathrm{df}=1 / 22, \mathrm{p}<.02)$. Later in training, there is very little apparent difference in performance of Groups 1-500 and 1-45. An analysis of the data confirmed the impression $(F=1.01)$.

\section{EXPERIMENT 2}

The series of studies involving consistent reward with different magnitudes suggests that the partial reinforcement situation should also be investigated. Wagner (1961) found that larger rewards gave more vigorous performance and greater resistance to extinction when given on a random partial reinforcement schedule. Wagner ran two levels of training, 16 and 60 trials. The present study included a group given extended training, since extended training appears to change the consistent reward situation.

Subjects and Apparatus

The Ss were 44 rats of the Long-Evans strain from the colony of the University of Texas at Arlington. All Ss were approximately 90 days old at the beginning of training. Approximately equal numbers of each sex were used. The apparatus was the same as that used in Experiment 1.

\section{Procedure}

Ss were placed on 23-h deprivation on Day 1 and handled and fed on Days 2-6. Ss explored the test alley on Days 7-10 for approximately 5 min daily. On Day 9 , Ss were divided into two groups, on a random basis. Group 45 was to receive one $45-\mathrm{mg}$ Noyes pellet as reward and Group 500 was to receive one 500-mg pellet. On Days 9 and 10, Ss received one goalbox (GB) placement per day with the appropriate reward. On Day 11, each $S$ received two running trials, four trials on Day 12, and six trials per day thereafter. A schedule of $50 \%$ random reward was used. Ss were 

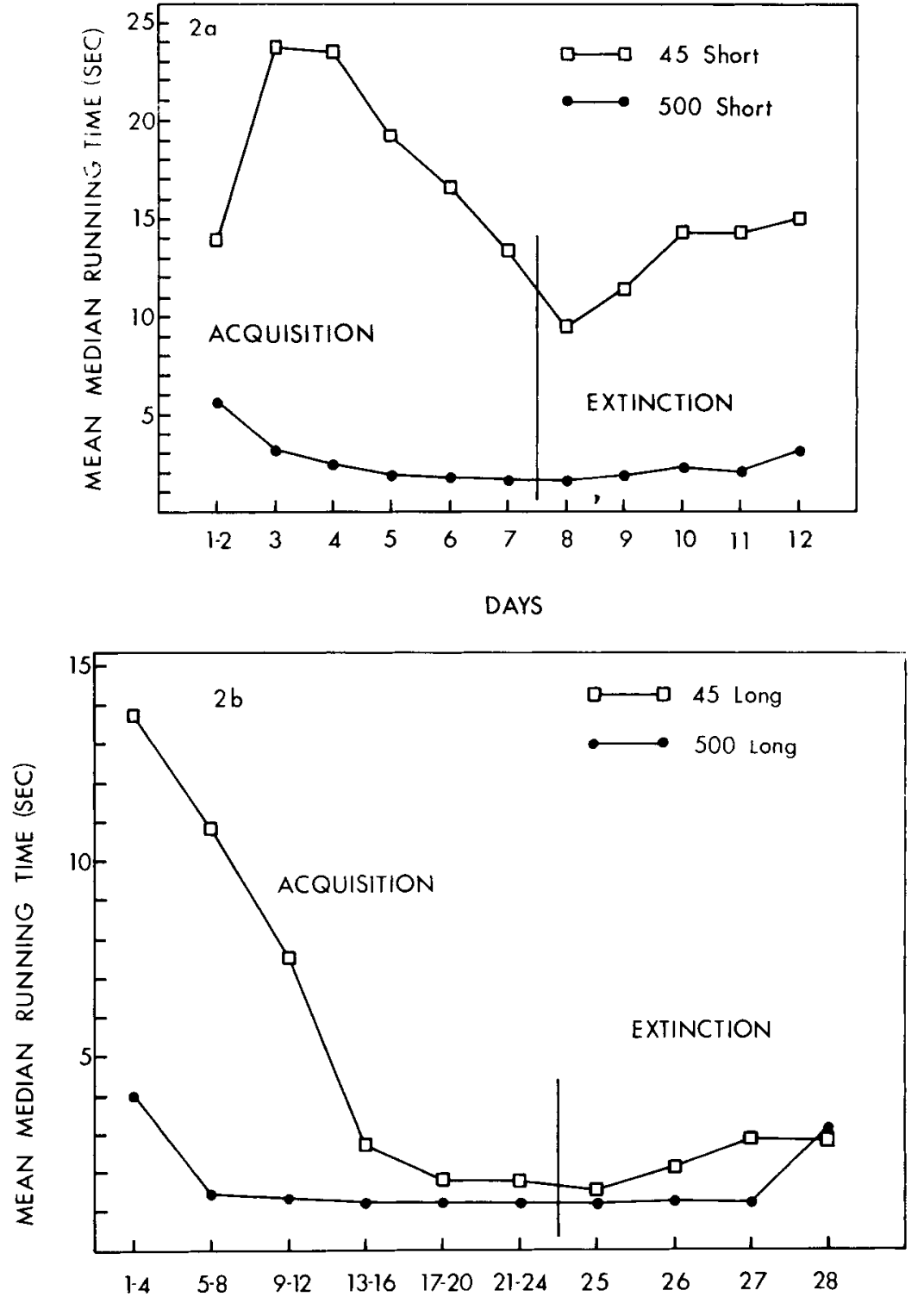

DAYS
Fig. 2. a and b. Running times for groups given partial 45- or 500-mg reward at two levels of acquisition training.

the small reward group declines sligh tly but not significantly more than the large-reward group.

\section{DISCUSSION}

Taken alone, these two studies are not sufficient to convince anyone that the effects of reward magnitude are sharply decreased or disappear after extended training. A series of nine other consistent reward studies has been run in our laboratory. Six of these studies have been put into one paper that is now under editorial consideration. In addition, Black (in press) and Bloom \& Milstead (1969) have substantial evidence that, during acquisition, magnitude differences disappear under some conditions. A reasonable conclusion is that after about 60 consistently reinforced acquisition trials in a straight alley, the acquisition effects of different reward magnitudes are either minimal or absent. Our other studies indicate that extinction differences disappear or become minimal after about $100+$ consistently reinforced acquisition trials. The situation as regards random partial reinforcement is not so clear. The study presented here is our only complete study of its kind. Single studies must, of necessity, be received with substantial skepticism. Further work is under way.

A number of possible confounding variables such as drive level, strain of animals, sampling, weight of Ss, particular reward magnitudes, pretraining, and performance within days, are obvious. Any or all of these could explain the results. Hopefully, presentation of the entire series of studies will cast some light on these problems, since a number of possibly effective variables have been considered.

The results presented here are contrary to usual assumptions about the effects of reward magnitude and, if supported, pose a problem for most learning theories. Spence (1956) speculated about the possibility that response differences related to reward magnitude might disappear after extended training. His analysis, based on the time required to condition $\mathrm{r}_{\mathrm{g}}$ to asymptote, is a possible explanation, but at this point the phenomena appear too complex for this type of analysis. Logan (1960) considered fear reduction as a possible role of increasing magnitude. This notion has yet to be tested. Since the data are limited and the situation appears complex, a statement of current results without extensive theoretical analysis seems reasonable. 


\section{REFERENCES}

BLACK, R. W. Incentive motivation and the parameters of reward in instrumental conditioning. Nebraska Symposium, in press.

BLOOM, J. M., \& MILSTEAD, J. Interactive effect of reward magnitude and intertrial interval on extinction behavior. Paper presented at Psychonomic Society Meeting, November 1969.

LOGAN, F. A. Incentive: How the conditions of reinforcement affect the performance of rats. New Haven: Yale University Press, 1960.

McCAIN, G. Magnitude effects after extended training. Paper presented at Psychonomic Society Meeting, November 1969.

SPENCE, K. W. Behavior theory and

\section{Correlates of food competition behavior ${ }^{1}$}

MARTIN MANOSEVITZ, CHARLES I. FITZSIMMONS, and THOMAS $R$. McCANNE, The University of Texas at Austin, Austin, Tex. 78712

Random-bred mice from a five-way cross of inbred strains were tested in the open field, running wheel, and food competition tests. various measures were intercorrelated to determine the associations between these behaviors. The results indicated that food competition behavior was positively associated with early running wheel activity, negatively correlated with open-field defecation, and negatively correlated with body weight measures There was no association between open-field activity and food competition. It was suggested that food competition behavior is partly determined by general activity and emotionality.

The ability of some members of a species to compete successfully against others for a limited food supply has survival value for the individual and could play an important role in natural selection and evolution. Diverse behaviors that may be important in natural selection, such as learning, emotionality, and activity, have often been studied by behavior geneticists, but social behaviors have been studied less often. The present experiment is concerned with studying, under laboratory conditions, the ability to compete for a limited food supply. The purpose of this experiment is to measure some possible correlates of food competition behavior, and to determine if this behavior is highly associated with other, particularly nonsocial, behaviors.

Food competition is a complex multidimensional behavioral pattern, and it is reasonable to assume that one or more simple behaviors or variables, like body conditioning. New Haven: Yale University Press, 1956.

WAGNER, A. R. Effects of amount and percentage of reinforcement and number of acquisition trials on conditioning and extinction. Journal of Experimental Psychology, 1961, 62, 234-242.

NOTE

1. These studies were supported in part by the Liberal Arts Organized Research Fund of the University of Texas at Arlington and in part by NIMH Grant No. 14686-01. Thanks are due to Kenneth Dyleski, who ran Experiment 1, and to Earl Isbell and Gary Gowins, who ran Experiment 2 . weight, may be associated with this behavior. To test this assumption, one may intercorrelate several measures with food competition scores and, in this way, determine the association between the various measures. If food competition performance is highly correlated with other, less complex behaviors, such as activity or emotionality, then behavior-genetic analyses of food competition must control for such factors.

In behavior genetic studies, intercorrelations between measures have seldom been reported. In many of these studies, inbred strains of mice were used and thus genetic variation was greatly reduced. When inbred strains are studied, intercorrelations within strains do not provide meaningful estimates of the interrelationships between variables because genetic and environmental variation is usually quite constricted. In fact, genetic variation should be close to zero, and if rigid laboratory conditions are maintained, environmental variation should be quite low. If intercorrelations between strains are computed, a large number of strains must be used because each strain is comparable to one individual. An alternate approach is to use mice that are genetically heterozygous. Such populations can be obtained by specific crosses, i.e., $F_{2} S$ and backcrosses or from a randomly bred line of mice. In this study, the latter approach was used.

$A$ random-bred line insures adequate genetic variation between animals to make correlation techniques appropriate. In this experiment, a laboratory-generated random-bred line of mice was used and each $S$ was measured on a number of behavioral traits; thus, it was possible to identify correlates of food competition behavior.

\section{METHOD}

A total of 60 (24 males, 36 females) 10th generation random-bred mice ${ }^{2}$ were used as Ss. The random line was constituted by crossing five inbred strains to form a foundation population. The five-way cross was generated by taking animals from the $\mathrm{RIII} / \mathrm{Crgl}$, C57BL/Crgl, $\mathrm{C} 3 \mathrm{H} / \mathrm{Crgl} / 2$, and $\mathrm{DBA} / \mathrm{Crgl} / 2$ inbred strains and crossing them, and then the fifth inbred strain, IsBi/Crgl, was added to the gene pool. Successive generations were produced by random mating.

Half the animals were exposed to an enriched environment from birth to 35 days of age. The details of this treatment and the test apparatus have been described by Manosevitz. ${ }^{3}$ Each $S$, starting at 38 days of age, was tested for 5 days in the open field, and urination, defecation, and activity were recorded. Between 70 and 107 days of age, each animal was tested in standard running wheels (Wahmann LC-34) for 4 consecutive days. Data from all but three Ss were available on the running wheel measure, because wheels malfunctioned for these animals. Activity readings were taken at the end of 30,60 , and $90 \mathrm{~min}$ and at the end of $24,48,72$, and $96 \mathrm{~h}$. Ss were started in the food competition test when they were between 95 and 156 days of age. The food competition test consisted of 5 days of

Table 1

Intercorrelation Matrix

\begin{tabular}{|c|c|c|c|c|c|c|c|c|c|}
\hline $\begin{array}{c}\text { Variable }^{\mathrm{a}} \\
1 \\
\end{array}$ & 2 & 3 & 4 & 5 & $6^{\mathrm{b}}$ & 7 & 8 & 9 & 10 \\
\hline $\begin{array}{l}1 \\
2 \\
3 \\
4 \\
5 \\
6 \\
7 \\
8 \\
9\end{array}$ & -.08 & $\begin{array}{c}.18 \\
-.32 *\end{array}$ & $\begin{array}{r}.17 \\
-.27 * \\
.41^{*}\end{array}$ & $\begin{array}{r}.05 \\
-.11 \\
.01 \\
.53^{*}\end{array}$ & $\begin{array}{c}-.07 \\
-.27^{*} \\
.11 \\
.28^{*} \\
.21\end{array}$ & $\begin{array}{c}-.15 \\
-.29^{*} \\
.16 \\
.34^{*} \\
.20 \\
.79^{*}\end{array}$ & $\begin{array}{c}.09 \\
-.27^{*} \\
.08 \\
.37^{*} \\
.28^{*} \\
.36^{*} \\
.50^{*}\end{array}$ & $\begin{array}{c}.01 \\
-.26^{*} \\
.03 \\
-.23^{*} \\
-.13 \\
-.20 \\
-.30^{*} \\
-.36^{*}\end{array}$ & $\begin{array}{c}.03 \\
-.33^{*} \\
.09 \\
-.17 \\
-.18 \\
-.16 \\
-.24^{*} \\
-.38^{*} \\
.90^{*}\end{array}$ \\
\hline
\end{tabular}

$a=60$ for all variables except 4 and $5 . N=57$ (running wheels malfunctioned for three $S$ s) See text for identification of variables.

$b$ Product-moment correlation for all variables except 6 which is point-biserial $* p<.05$ 